\title{
ADJUSTMENT COSTS IN A TWO-CAPITAL GROWTH MODEL
}

\author{
Petr Duczynski*
}

May, 1999

\begin{abstract}
The paper analyzes the convergence dynamics of a log-linearized openeconomy neoclassical growth model under the assumptions of large adjustment costs for human capital investment, moderate adjustment costs for physical capital investment, and perfect capital mobility. The model can be calibrated for sufficiently slow conditional convergence. The model's dynamics turn out to be richer than the dynamics of the basic neoclassical model due to the imbalance effect between human and physical capital.
\end{abstract}

\begin{abstract}
Abstrakt
Článek analyzuje konvergenční dynamiku log-linearizovaného neoklasického růstového modelu otevřené ekonomiky za předpokladu vysokých instalačních nákladů pro investice do lidského kapitálu, nižších instalačních nákladi̊ pro investice do fyzického kapitálu a dokonalé kapitálové pohyblivosti. Model lze kalibrovat pro dostatečně pomalou podmíněnou konvergenci. Dynamika modelu vychází bohatší ve srovnání s dynamikou základního neoklasického modelu vzhledem k imbalančnímu efektu mezi lidským a fyzickým kapitálem.
\end{abstract}

${ }^{*}$ CERGE-EI, Politických vězñů 7, 11121 Prague 1, Czech Republic, email: petr.duczynski@cerge.cuni.cz. I am grateful to Robert Barro, Michal Kejak, Jan Kmenta, David Laibson, Jordan Rappaport, Stanley Reynolds, András Simonovits, Viatcheslav Vinogradov, and the participants of the Workshop in Macroeconomic Research at Harvard University for helpful comments. I am fully responsible for any remaining errors. 


\section{Introduction}

The basic neoclassical growth model (Solow [15]) predicts counterfactual implications when applied to open economies with perfect capital mobility. If technological differences are not great between rich and poor economies, the law of diminishing returns results in higher rates of return in poor economies. Therefore, the model implies infinitely rapid capital flows from rich to poor economies, equalization of the rates of return across all open economies, and immediate convergence of capital and output to their steady-state levels.

Such a scenario is clearly inconsistent with empirical observations. Capital flows from rich to poor economies are not typically extremely large. ${ }^{1}$ Analogously, open economies have not been found to converge quickly to their steady states. Barro and Sala-i-Martin [3], Chapters 11 and 12, find that both regions within countries (more open economies) and individual countries (less open economies) converge to their steady states at the rate of about 2 percent per year.

Several modifications of the neoclassical model have been developed to avoid the model's unrealistic implications. ${ }^{2}$ Such modifications include, for example, borrowing restrictions. In Barro et al.'s [4] model, physical capital can be financed by borrowing on the world credit market, whereas human capital cannot. This provides an elegant explanation for the slow convergence of open creditconstrained economies. (Human capital accumulation cannot be rapid because human capital requires financing by domestic residents. Consequently, relatively low levels of human capital discourage physical capital investment because human and physical capital are complements in production.) In this framework, the assumption of binding borrowing constraints is crucial for achieving slow convergence. Yet a large number of economies seem to be unconstrained. ${ }^{3}$

The present paper is inspired by Chapter 3 of Barro and Sala-i-Martin's [3] book and provides an alternative explanation for the slow convergence of open economies by developing a two-capital model with the adjustment costs for in-

\footnotetext{
${ }^{1}$ Lucas [12] argues that one reason why physical capital does not flow much to poor countries is their relative scarcity in human capital, which results in relatively low returns on physical capital. The present paper takes account of the role that human capital plays in determining physical capital returns.

${ }^{2}$ Barro and Sala-i-Martin [3] provide a more detailed analysis in Chapter 3.

${ }^{3}$ Elsewhere (Duczynski [9], available on request) I identify candidates for unconstrained countries and provide some evidence that borrowing constraints are not likely to be binding for the vast majority of the U.S. federal states.
} 
vestments in both types of capital. ${ }^{4}$ An important assumption is that the costs of adjustment are especially large for human capital investment. ${ }^{5}$ The model abstracts, for simplicity, from any borrowing restrictions.

The log-linearized approximation of the model is solved analytically. Large adjustment costs for human capital investment act in a similar manner as borrowing restrictions in Barro et al.'s [4] model do: if human capital cannot be changed rapidly, marginal products of physical capital remain relatively low and physical capital investment is correspondingly limited. The model can be calibrated for sufficiently slow conditional convergence. For a given level of output, the output growth rate is positively related to the ratio of human to physical capital if the multiplicative adjustment-cost parameter is higher for human than for physical capital. This implication of the model is consistent with numerous empirical observations. ${ }^{6}$

The paper is organized as follows. Section 2 discusses the problem of optimal investments in human and physical capital, specifies the adjustment-cost functions and derives the steady-state equilibrium. The model's log-linearization is developed in Section 3, which contains several propositions on the growth dynamics and provides some illustrative examples. Section 4 concludes the paper.

\section{The Model}

The model extends the analysis of Barro and Sala-i-Martin [3], Section 3.5, Blanchard and Fischer [5], Section 2.4, and Hayashi [10], where corresponding models with one kind of capital are developed. Assume a small open economy consisting of $N_{F}$ firms and $N_{H}$ households. Assume that firms make decisions on physical capital investment, whereas households decide on human capital investment. Firms borrow the uninstalled physical capital from households, paying dividends on it to households. Households supply firms with the installed human capital

\footnotetext{
${ }^{4}$ Adjustment costs have been used in several macroeconomic models with one kind of capital. Abel and Blanchard [1] develop a closed-economy neoclassical model with adjustment costs and endogenous saving decisions. Hayashi's [10] classic paper discusses the investment problem under adjustment costs.

${ }^{5}$ In the model of Kremer and Thomson [11], large adjustment costs for changing human capital effectively emerge as a result of complementarity between the human capital of young and old workers.

${ }^{6}$ Cross-country regressions following Barro's [2] classic contribution.
} 
and raw labor, on which they receive human capital returns, $r_{H}$, and wages, $w$, respectively.

\subsection{Physical Capital Investment}

Let the production of each firm be described by the Cobb-Douglas production function of the augmented neoclassical model. ${ }^{7}$ Let the technological progress be labor-augmenting at a constant, exogenous rate, $x$, so that the production of the $i$-th firm $\left(i=1,2, \ldots, N_{F}\right)$ is described by

$$
Y_{i}=F_{i}\left(K_{i}, H_{i}, L_{i} e^{x t}\right)=A K_{i}^{\alpha} H_{i}^{\eta}\left(L_{i} e^{x t}\right)^{1-\alpha-\eta},
$$

where $\alpha>0, \eta>0$, and $\alpha+\eta<1$. $Y_{i}$ is the firm's output, and $A$ is a fixed technological parameter (common to all firms). $K_{i}, H_{i}$, and $L_{i}$ are physical capital, human capital, and raw labor, respectively, employed by the $i$-th firm.

Let $I_{K_{i}}$ be the gross physical capital investment chosen by the $i$-th firm. Let the investment expenditures of that firm amount to $I_{K_{i}}\left[1+\phi_{k}\left(I_{K_{i}} / K_{i}\right)\right]$, where $\phi_{k}\left(I_{K_{i}} / K_{i}\right)$ is the unit adjustment cost for physical capital investment, satisfying $\phi_{k}(0)=0, \phi_{k}^{\prime}\left(I_{K_{i}} / K_{i}\right)>0$, and $\phi_{k}^{\prime \prime}\left(I_{K_{i}} / K_{i}\right) \geq 0{ }^{8}$

Let $r$ denote the world real interest rate. The firm's objective is to maximize the present discounted value of its dividends:

$$
\max _{I_{K_{i}}, H_{i}, L_{i}} \int_{0}^{\infty} e^{-r t}\left\{F_{i}\left(K_{i}, H_{i}, L_{i} e^{x t}\right)-w L_{i}-I_{K_{i}}\left[1+\phi_{k}\left(I_{K_{i}} / K_{i}\right)\right]-r_{H} H_{i}\right\} d t
$$

subject to

$$
\begin{gathered}
\dot{K}_{i}=I_{K_{i}}-\delta K_{i}, \\
K_{i}(0)=K_{i 0},
\end{gathered}
$$

where $\delta$ is the depreciation rate of physical capital; $K_{i}$ is a state variable, whereas $I_{K_{i}}, H_{i}$, and $L_{i}$ are control variables. The current-value Hamiltonian for this problem is

$$
\mathcal{J}_{i}=F_{i}\left(K_{i}, H_{i}, L_{i} e^{x t}\right)-w L_{i}-I_{K_{i}}\left[1+\phi_{k}\left(I_{K_{i}} / K_{i}\right)\right]-r_{H} H_{i}+q_{K_{i}}\left[I_{K_{i}}-\delta K_{i}\right],
$$

\footnotetext{
${ }^{7}$ See, for example, Barro et al. [4] or Mankiw et al. [13].

${ }^{8}$ Actually, even a weaker condition $2 \phi_{k}^{\prime}\left(I_{K_{i}} / K_{i}\right)+\left(I_{K_{i}} / K_{i}\right) \phi_{k}^{\prime \prime}\left(I_{K_{i}} / K_{i}\right) \geq 0$ would be sufficient to ensure the convexity of the cost function $I_{K_{i}} \phi_{k}\left(I_{K_{i}} / K_{i}\right)$.
} 
where $q_{K_{i}}$ is a co-state variable indicating the marginal shadow value of $K_{i}$. The first-order conditions are

$$
\begin{gathered}
\frac{\partial \mathcal{J}_{i}}{\partial I_{K_{i}}}=-\left[1+\phi_{k}\left(I_{K_{i}} / K_{i}\right)+\left(I_{K_{i}} / K_{i}\right) \phi_{k}^{\prime}\left(I_{K_{i}} / K_{i}\right)\right]+q_{K_{i}}=0 \\
\frac{\partial \mathcal{J}_{i}}{\partial H_{i}}=\frac{\partial F_{i}}{\partial H_{i}}-r_{H}=0 \\
\frac{\partial \mathcal{J}_{i}}{\partial L_{i}}=\frac{\partial F_{i}}{\partial L_{i}}-w=0 \\
\dot{q}_{K_{i}}=r q_{K_{i}}-\frac{\partial \mathcal{J}_{i}}{\partial K_{i}}=(r+\delta) q_{K_{i}}-\frac{\partial F_{i}}{\partial K_{i}}-\left(I_{K_{i}} / K_{i}\right)^{2} \phi_{k}^{\prime}\left(I_{K_{i}} / K_{i}\right) .
\end{gathered}
$$

The transversality condition is

$$
\lim _{t \rightarrow \infty} e^{-r t} q_{K_{i}} K_{i}=0
$$

$\frac{\partial F_{i}}{\partial K_{i}}$ does not depend on $i$ once $r_{H}$ and $w$ are given. This follows from the fact that the production function is assumed to exhibit constant returns to scale and to be identical for all firms. Equations (1), (5), and (6) imply that $H_{i}=\frac{\eta}{r_{H}} Y_{i}$ and $L_{i}=\frac{1-\alpha-\eta}{w} Y_{i}$. If this is substituted in (1), $\frac{\partial F_{i}}{\partial K_{i}}$ can be expressed in terms of $w$ and $r_{H}$ regardless of $i$. If $K_{i}(t)$ and $q_{K_{i}}(t)$ solve (4), (7), and (8) for given $K_{i 0}$, then $\xi K_{i}(t)$ and $q_{K_{i}}(t)$ solve $(4),(7)$, and (8) for given $\xi K_{i 0}$ (where $\xi$ is a positive real number). The equilibrium path of $I_{K_{i}} / K_{i}$ and $q_{K_{i}}$ is therefore independent of $i$. The path of the aggregate $K=\sum_{i=1}^{N_{F}} K_{i}$ is thus independent of the distribution of $K_{0}=\sum_{i=1}^{N_{F}} K_{i 0}$ among firms.

Let the other aggregate variables be defined in a similar manner: $Y=\sum_{i=1}^{N_{F}} Y_{i}$, $H=\sum_{i=1}^{N_{F}} H_{i}, L=\sum_{i=1}^{N_{F}} L_{i}$, and $I_{K}=\sum_{i=1}^{N_{F}} I_{K_{i}}$. Let the aggregate raw labor, $L$, grow at a constant, exogenous population growth rate, $n$, so that $L=L_{0} e^{n t}$. Let $y=Y /\left(L e^{x t}\right), k=K /\left(L e^{x t}\right), h=H /\left(L e^{x t}\right)$, and $i_{k}=I_{K} /\left(L e^{x t}\right)$ be corresponding variables per effective worker. Equations (2), (3), (4), (5), (7), and (8) can be rewritten in their intensive forms

$$
\begin{gathered}
\dot{k}=i_{k}-(\delta+n+x) k, \\
k(0)=k_{0}, \\
q_{k}=1+\phi_{k}\left(i_{k} / k\right)+\left(i_{k} / k\right) \phi_{k}^{\prime}\left(i_{k} / k\right), \\
\frac{\partial f}{\partial h}=r_{H},
\end{gathered}
$$




$$
\begin{gathered}
\dot{q}_{k}=(r+\delta) q_{k}-\frac{\partial f}{\partial k}-\left(i_{k} / k\right)^{2} \phi_{k}^{\prime}\left(i_{k} / k\right), \\
\lim _{t \rightarrow \infty} e^{-(r-x-n) t} q_{k} k=0,
\end{gathered}
$$

where $k_{0}=K_{0} /\left(L e^{x t}\right), q_{k}$ stands for the common value of $q_{K_{i}}$, and

$$
y=f(k, h)=A k^{\alpha} h^{\eta}
$$

\subsection{Human Capital Investment}

Households choose the optimal human capital investment by maximizing the discounted stream of their human capital income net of investment expenditures. Let $H^{j}$ and $I_{H^{j}}$ denote the human capital level and the gross human capital investment of the $j$-th household $\left(j=1,2, \ldots, N_{H}\right)$, respectively. Let the unit adjustment costs for changing human capital be $\phi_{h}\left(I_{H^{j}} / H^{j}\right)$ for the $j$-th household, where $\phi_{h}(0)=0, \phi_{h}^{\prime}\left(I_{H^{j}} / H^{j}\right)>0$, and $\phi_{h}^{\prime \prime}\left(I_{H^{j}} / H^{j}\right) \geq 0$. The problem of the $j$-th household takes the form

$$
\max _{I_{H^{j}}} \int_{0}^{\infty} e^{-r t}\left\{r_{H} H^{j}-I_{H^{j}}\left[1+\phi_{h}\left(I_{H^{j}} / H^{j}\right)\right]\right\} d t
$$

subject to

$$
\begin{gathered}
\dot{H}^{j}=I_{H^{j}}-\delta H^{j} \\
H^{j}(0)=H_{0}^{j}
\end{gathered}
$$

[For simplicity, the depreciation rate, $\delta$, is assumed to be the same for both human and physical capital. The depreciation of human capital reflects the depreciation on the individual level (forgetting), as well as the imperfections in the intergenerational transmission of human capital.] The current-value Hamiltonian for this problem is

$$
\mathcal{K}^{j}=r_{H} H^{j}-I_{H^{j}}\left[1+\phi_{h}\left(I_{H^{j}} / H^{j}\right)\right]+q_{H^{j}}\left[I_{H^{j}}-\delta H^{j}\right],
$$

where $q_{H^{j}}$ is a co-state variable indicating the marginal shadow value of human capital. The first-order conditions are

$$
\begin{gathered}
\frac{\partial \mathcal{K}^{j}}{\partial I_{H^{j}}}=-\left[1+\phi_{h}\left(I_{H^{j}} / H^{j}\right)+\left(I_{H^{j}} / H^{j}\right) \phi_{h}^{\prime}\left(I_{H^{j}} / H^{j}\right)\right]+q_{H^{j}}=0, \\
\dot{q}_{H^{j}}=r q_{H^{j}}-\frac{\partial \mathcal{K}^{j}}{\partial H^{j}}=(r+\delta) q_{H^{j}}-r_{H}-\left(I_{H^{j}} / H^{j}\right)^{2} \phi_{h}^{\prime}\left(I_{H^{j}} / H^{j}\right) .
\end{gathered}
$$


The transversality condition is

$$
\lim _{t \rightarrow \infty} e^{-r t} q_{H^{j}} H^{j}=0 .
$$

The time evolution of $I_{H^{j}} / H^{j}$ and $q_{H^{j}}$ is independent of $j$; consequently, the time paths of $I_{H}=\sum_{j=1}^{N_{H}} I_{H^{j}}$ and $H=\sum_{j=1}^{N_{H}} H^{j}$ are independent of the distribution of $H_{0}=\sum_{j=1}^{N_{H}} H_{0}^{j}$ among households. Equations (16)-(20) can be rewritten in their intensive forms

$$
\begin{gathered}
\dot{h}=i_{h}-(\delta+n+x) h, \\
h(0)=h_{0}, \\
q_{h}=1+\phi_{h}\left(i_{h} / h\right)+\left(i_{h} / h\right) \phi_{h}^{\prime}\left(i_{h} / h\right), \\
\dot{q}_{h}=(r+\delta) q_{h}-r_{H}-\left(i_{h} / h\right)^{2} \phi_{h}^{\prime}\left(i_{h} / h\right), \\
\lim _{t \rightarrow \infty} e^{-(r-x-n) t} q_{h} h=0,
\end{gathered}
$$

where $i_{h}=I_{H} /\left(L e^{x t}\right), h_{0}=H_{0} /\left(L e^{x t}\right)$, and $q_{h}$ stands for the common value of $q_{H^{j}}$.

Because (11) and (23) imply increasing relationships between $q_{k}$ and $i_{k} / k$, and between $q_{h}$ and $i_{h} / h$, respectively, it is possible to express $i_{k} / k$ and $i_{h} / h$ in terms of $q_{k}$ and $q_{h}$, respectively:

$$
\begin{aligned}
& \frac{i_{k}}{k}=\Psi_{k}\left(q_{k}\right), \\
& \frac{i_{h}}{h}=\Psi_{h}\left(q_{h}\right),
\end{aligned}
$$

where $\Psi_{k}($.$) and \Psi_{h}($.$) are inverse functions of those expressed in (11) and (23). { }^{9}$ Substituting (12), (26) and (27) into (9), (21), (13), and (24) leads to

$$
\begin{gathered}
\frac{\dot{k}}{k}=\Psi_{k}\left(q_{k}\right)-(\delta+n+x), \\
\frac{\dot{h}}{h}=\Psi_{h}\left(q_{h}\right)-(\delta+n+x), \\
\frac{\dot{q}_{k}}{q_{k}}=r+\delta-\frac{\frac{\partial f}{\partial k}+\Psi_{k}^{2}\left(q_{k}\right) \phi_{k}^{\prime}\left[\Psi_{k}\left(q_{k}\right)\right]}{q_{k}}, \\
\frac{\dot{q}_{h}}{q_{h}}=r+\delta-\frac{\frac{\partial f}{\partial h}+\Psi_{h}^{2}\left(q_{h}\right) \phi_{h}^{\prime}\left[\Psi_{h}\left(q_{h}\right)\right]}{q_{h}} .
\end{gathered}
$$

\footnotetext{
${ }^{9}$ Note that $\Psi_{k}^{\prime}()>$.0 and $\Psi_{h}^{\prime}()>$.0 .
} 
The behavior of $k$ and $h$ is described by (28)-(31) and by the initial and transversality conditions; ${ }^{10}$ therefore, it can be studied separately from the behavior of consumption.

\subsection{Adjustment Costs Specifications}

The system (28)-(31) cannot be easily analyzed for general forms of adjustment costs specifications, $\phi_{k}($.$) and \phi_{h}($.$) . We assume, for simplicity, that$

$$
\begin{aligned}
& \phi_{k}\left(i_{k} / k\right)=\frac{b_{k}}{\omega+1}\left(i_{k} / k\right)^{\omega}, \\
& \phi_{h}\left(i_{h} / h\right)=\frac{b_{h}}{\omega+1}\left(i_{h} / h\right)^{\omega},
\end{aligned}
$$

where $\omega \geq 1,{ }^{11} b_{k}>0$, and $b_{h}>0 .{ }^{12}$ The problem simplifies to the following:

$$
\begin{gathered}
q_{k}=1+b_{k}\left(i_{k} / k\right)^{\omega}, \\
q_{h}=1+b_{h}\left(i_{h} / h\right)^{\omega}, \\
\Psi_{k}\left(q_{k}\right)=\left[\left(q_{k}-1\right) / b_{k}\right]^{1 / \omega}, \\
\Psi_{h}\left(q_{h}\right)=\left[\left(q_{h}-1\right) / b_{h}\right]^{1 / \omega}, \\
\frac{\dot{k}}{k}=\left[\left(q_{k}-1\right) / b_{k}\right]^{1 / \omega}-(x+n+\delta), \\
\frac{\dot{h}}{h}=\left[\left(q_{h}-1\right) / b_{h}\right]^{1 / \omega}-(x+n+\delta), \\
\frac{\dot{q}_{k}}{q_{k}}=r+\delta-\frac{\frac{\partial f}{\partial k}+\left(q_{k}-1\right)^{(1+1 / \omega)} b_{k}^{-1 / \omega} \omega /(1+\omega)}{q_{k}}, \\
\frac{\dot{q}_{h}}{q_{h}}=r+\delta-\frac{\frac{\partial f}{\partial h}+\left(q_{h}-1\right)^{(1+1 / \omega)} b_{h}^{-1 / \omega} \omega /(1+\omega)}{q_{h}} .
\end{gathered}
$$

\footnotetext{
${ }^{10}$ The Supplement (available on request) shows that this decentralized outcome is Pareto efficient.

${ }^{11}$ The term $\omega+1$ in the denominator simplifies the subsequent analysis.

${ }^{12}$ We do not impose irreversibility restrictions on investment; therefore, problems might arise if gross investment were negative. These difficulties can be technically mitigated by restricting $\omega$ to odd rational numbers (i.e., numbers expressed as ratios of two odd integers). In this case, disinvestment is costly, and adjustment costs act effectively as (imperfect) irreversibility constraints. Similar problems do not, however, occur in the neighborhood of the steady state, where gross investment is positive.
} 


\subsection{The Steady State}

Let all relevant variables be required to grow at constant rates (which are neither necessarily identical nor necessarily equal to zero) in a steady state. Equations (38) and (39) imply that $q_{k}$ and $q_{h}$ are constant in the steady state, which means that the steady-state growth rate is zero for $q_{k}$ and $q_{h}$. Equations (40) and (41) state that this is achieved if and only if the marginal products of $f(k, h)$ stay constant. The constancy of the marginal products requires a constancy of $k$ and $h$ (due to diminishing returns to broad capital). Both (14) and (25) then lead to $r-x-n>0$, which constitutes a restriction on the exogenous parameters $r, x$, and $n$.

Let $q_{k}^{*}, q_{h}^{*}, k^{*}$, and $h^{*}$ denote the steady-state levels of $q_{k}, q_{h}, k$, and $h$, respectively. The steady-state levels of $q_{k}$ and $q_{h}$ satisfy

$$
\begin{aligned}
& q_{k}^{*}=1+b_{k}(x+n+\delta)^{\omega}, \\
& q_{h}^{*}=1+b_{h}(x+n+\delta)^{\omega} .
\end{aligned}
$$

The steady-state values of $k$ and $h$ can be determined from the steady-state marginal products:

$$
\begin{gathered}
\left(\frac{\partial f}{\partial k}\right)^{*}=A \alpha k^{* \alpha-1} h^{* \eta}=r+\delta+b_{k}(x+n+\delta)^{\omega}[r+\delta-(x+n+\delta) \omega /(1+\omega)] \\
\left(\frac{\partial f}{\partial h}\right)^{*}=A \eta k^{* \alpha} h^{* \eta-1}=r+\delta+b_{h}(x+n+\delta)^{\omega}[r+\delta-(x+n+\delta) \omega /(1+\omega)] \\
k^{* 1-\alpha-\eta}=A\left(\frac{\partial f}{\partial k}\right)^{* \eta-1}\left(\frac{\partial f}{\partial h}\right)^{*-\eta} \alpha^{1-\eta} \eta^{\eta} \\
h^{* 1-\alpha-\eta}=A\left(\frac{\partial f}{\partial k}\right)^{*-\alpha}\left(\frac{\partial f}{\partial h}\right)^{* \alpha-1} \alpha^{\alpha} \eta^{1-\alpha} \\
h^{*} / k^{*}=\frac{\eta}{\alpha}\left(\frac{\partial f}{\partial k}\right)^{*}\left(\frac{\partial f}{\partial h}\right)^{*-1} \cdot
\end{gathered}
$$

The steady-state output per effective capita, $y^{*}$, satisfies

$$
y^{* 1-\alpha-\eta}=A\left(\frac{\partial f}{\partial k}\right)^{*-\alpha}\left(\frac{\partial f}{\partial h}\right)^{*-\eta} \alpha^{\alpha} \eta^{\eta} .
$$

From this it follows that for plausible parameter values, $y^{*}$ depends positively on $A$ and $\omega$, and negatively on $b_{k}, b_{h}, r, x, n$, and $\delta .{ }^{13}$

\footnotetext{
${ }^{13}$ The dependency on $A, b_{k}, b_{h}$, and $r$ is trivial; the dependency on $\omega, x, n$, and $\delta$ can be derived analytically.
} 


\section{Log-Linearized Approximation}

Using Taylor's expansion, we can log-linearize the system of four differential equations (38)-(41) around the steady state: ${ }^{14}$

$$
\left(\begin{array}{c}
\frac{d \ln \left(k / k^{*}\right)}{d t} \\
\frac{d \ln \left(q_{k} / q_{k}^{*}\right)}{d t} \\
\frac{d \ln \left(h / h^{*}\right)}{d t} \\
\frac{d \ln \left(q_{h} / q_{h}^{*}\right)}{d t}
\end{array}\right)=\left(\begin{array}{cccc}
0 & \mathcal{A} & 0 & 0 \\
\mathcal{B} & \mathcal{C} & \mathcal{D} & 0 \\
0 & 0 & 0 & \mathcal{E} \\
\mathcal{F} & 0 & \mathcal{G} & \mathcal{C}
\end{array}\right)\left(\begin{array}{c}
\ln \left(k / k^{*}\right) \\
\ln \left(q_{k} / q_{k}^{*}\right) \\
\ln \left(h / h^{*}\right) \\
\ln \left(q_{h} / q_{h}^{*}\right)
\end{array}\right),
$$

where

$$
\begin{gathered}
\mathcal{A}=\frac{q_{k}^{*}}{b_{k} \omega}\left[\left(q_{k}^{*}-1\right) / b_{k}\right]^{(1 / \omega)-1}>0, \\
\mathcal{B}=\frac{1-\alpha}{q_{k}^{*}}\left(\frac{\partial f}{\partial k}\right)^{*}>0, \\
\mathcal{C}=\frac{\left(\frac{\partial f}{\partial k}\right)^{*}}{q_{k}^{*}}-\frac{b_{k}^{-1 / \omega} \omega /(1+\omega)}{q_{k}^{*}}\left(q_{k}^{*}-1\right)^{1 / \omega}\left(1+\frac{q_{k}^{*}}{\omega}\right)=r-x-n>0, \\
\mathcal{D}=-\frac{\eta}{q_{k}^{*}}\left(\frac{\partial f}{\partial k}\right)^{*}<0, \\
\mathcal{E}=\frac{q_{h}^{*}}{b_{h} \omega}\left[\left(q_{h}^{*}-1\right) / b_{h}\right]^{(1 / \omega)-1}>0, \\
\mathcal{F}=-\frac{\alpha}{q_{h}^{*}}\left(\frac{\partial f}{\partial h}\right)^{*}<0, \\
\mathcal{G}=\frac{1-\eta}{q_{h}^{*}}\left(\frac{\partial f}{\partial h}\right)^{*}>0 .
\end{gathered}
$$

The key problem now is to find the eigenvalues of the Jacobian matrix

$$
\left(\begin{array}{llll}
0 & \mathcal{A} & 0 & 0 \\
\mathcal{B} & \mathcal{C} & \mathcal{D} & 0 \\
0 & 0 & 0 & \mathcal{E} \\
\mathcal{F} & 0 & \mathcal{G} & \mathcal{C}
\end{array}\right)
$$

\footnotetext{
${ }^{14}$ The log-linearization describes the behavior of the economy locally around the steady state. This approach allows for an analytical solution; it gets, however, imprecise for economies which are distant from their steady states. Future research could focus on numerical solutions to the exact equations (38)-(41).
} 
These eigenvalues, $\epsilon$, are the roots of the characteristic equation, which is a fourth-order algebraic equation:

$$
\epsilon^{4}-2 \mathcal{C} \epsilon^{3}+\left(\mathcal{C}^{2}-\mathcal{E} \mathcal{G}-\mathcal{A B}\right) \epsilon^{2}+\mathcal{C}(\mathcal{A B}+\mathcal{E} \mathcal{G}) \epsilon+\mathcal{A} \mathcal{E}(\mathcal{B G}-\mathcal{D F})=0
$$

Solutions to fourth-order algebraic equations can be expressed in analytical forms; however, this procedure is relatively cumbersome. Luckily, (57) takes a special form which can be decomposed into a product of two quadratic equations. This can be done because $\mathcal{D} \mathcal{F}=\frac{\alpha \eta}{(1-\alpha)(1-\eta)} \mathcal{B G}$. Let there be two general quadratic equations:

$$
\begin{aligned}
& \epsilon^{2}+z_{1} \epsilon+z_{2}=0, \\
& \epsilon^{2}+z_{3} \epsilon+z_{4}=0 .
\end{aligned}
$$

The product of these two equations is

$$
\epsilon^{4}+\left(z_{1}+z_{3}\right) \epsilon^{3}+\left(z_{2}+z_{4}+z_{1} z_{3}\right) \epsilon^{2}+\left(z_{1} z_{4}+z_{2} z_{3}\right) \epsilon+z_{2} z_{4}=0
$$

We obtain the characteristic equation (57) if we choose $z_{1}, z_{2}, z_{3}$, and $z_{4}$ in the following way:

$$
\begin{gathered}
z_{1}=z_{3}=-\mathcal{C}=x+n-r<0, \\
z_{2}+z_{4}=-(\mathcal{A B}+\mathcal{E} \mathcal{G}), \\
z_{2} z_{4}=\frac{\mathcal{A B E} \mathcal{G}(1-\alpha-\eta)}{(1-\alpha)(1-\eta)} .
\end{gathered}
$$

The solution to the last two equations is

$$
z_{2 ; 4}=\frac{-\mathcal{E} \mathcal{G}-\mathcal{A B} \pm \sqrt{(\mathcal{A B}+\mathcal{E} \mathcal{G})^{2}-4 \mathcal{A B \mathcal { E } G} \frac{1-\alpha-\eta}{(1-\alpha)(1-\eta)}}}{2}<0
$$

i.e., we assume $z_{4}<z_{2}$.

Two eigenvalues of the Jacobian matrix are positive and two eigenvalues are negative. The positive eigenvalues correspond to explosive paths and must consequently be excluded for the transversality conditions to be satisfied. The model's structure of two state and two control variables with two negative eigenvalues of the Jacobian matrix implies a "saddle-hyperplane" stability. The stable manifold is given by a two-dimensional hyperplane in a four-dimensional hyperspace. ${ }^{15}$

\footnotetext{
${ }^{15}$ Caballe and Santos [7] have also analyzed a problem with two state and two control variables, although in an endogenous growth model. In comparison, their model exhibits a ray of steady states and one-dimensional stable manifolds locally associated with each steady-state point.
} 
The two negative eigenvalues are

$$
\epsilon_{1 ; 2}=\frac{r-x-n-\sqrt{(r-x-n)^{2}-4 z_{2 ; 4}}}{2}<0,
$$

and $\epsilon_{2}<\epsilon_{1}$ follows from $z_{4}<z_{2}$. The time evolution of $k, q_{k}, h$, and $q_{h}$ is

$$
\begin{gathered}
\ln \left(k / k^{*}\right)=\mu_{1} e^{\epsilon_{1} t}+\mu_{2} e^{\epsilon_{2} t}, \\
\ln \left(q_{k} / q_{k}^{*}\right)=\nu_{1,1} \mu_{1} e^{\epsilon_{1} t}+\nu_{2,1} \mu_{2} e^{\epsilon_{2} t}, \\
\ln \left(h / h^{*}\right)=\nu_{1,2} \mu_{1} e^{\epsilon_{1} t}+\nu_{2,2} \mu_{2} e^{\epsilon_{2} t}, \\
\ln \left(q_{h} / q_{h}^{*}\right)=\nu_{1,3} \mu_{1} e^{\epsilon_{1} t}+\nu_{2,3} \mu_{2} e^{\epsilon_{2} t},
\end{gathered}
$$

where $\left(1, \nu_{i, 1}, \nu_{i, 2}, \nu_{i, 3}\right)$ is the eigenvector corresponding to eigenvalue $\epsilon_{i}(i=1,2)$ :

$$
\begin{gathered}
\nu_{i, 1}=\frac{\epsilon_{i}}{\mathcal{A}}, \\
\nu_{i, 2}=-\frac{\mathcal{B}+\epsilon_{i}\left(\mathcal{C}-\epsilon_{i}\right) / \mathcal{A}}{\mathcal{D}}=-\frac{\mathcal{B}+z_{2 i} / \mathcal{A}}{\mathcal{D}}, \\
\nu_{i, 3}=\frac{\epsilon_{i}}{\mathcal{E}} \nu_{i, 2},
\end{gathered}
$$

where $z_{2 i}$ in (71) is meant to be $z_{2}$ and $z_{4}$ for $i=1$ and $i=2$, respectively. Coefficients $\mu_{1}$ and $\mu_{2}$ can be determined from the initial conditions for $k$ and $h$ :

$$
\begin{aligned}
& \mu_{1}=\frac{\ln \left(h_{0} / h^{*}\right)-\nu_{2,2} \ln \left(k_{0} / k^{*}\right)}{\nu_{1,2}-\nu_{2,2}}, \\
& \mu_{2}=\frac{\ln \left(h_{0} / h^{*}\right)-\nu_{1,2} \ln \left(k_{0} / k^{*}\right)}{\nu_{2,2}-\nu_{1,2}} .
\end{aligned}
$$

Note that $\nu_{1,2}>\nu_{2,2}$ follows from $z_{4}<z_{2}$. Equations (66)-(74) determine the time evolution of $k, q_{k}, h$, and $q_{h}$ for given parameter values and initial conditions $k_{0}$ and $h_{0}$. Note that $\epsilon_{1}<0$ and $\epsilon_{2}<0$ imply that the right-hand sides of (66)-(69) converge to 0 for $t \rightarrow \infty$, which is consistent with the convergence of the variables to their steady-state levels. The system behavior differs, however, from that of the basic neoclassical model of a closed economy. ${ }^{16}$ There are two exponential terms here, and the model's dynamics are correspondingly richer. Since $\left|\epsilon_{1}\right|<\left|\epsilon_{2}\right|$, the term with $\epsilon_{2}$ may be important initially, but it diminishes over time and the term with $\epsilon_{1}$ dominates asymptotically.

\footnotetext{
${ }^{16}$ The behavior of the log-linearized basic neoclassical model is discussed, for example, in Barro and Sala-i-Martin [3], Chapter 1.
} 


\subsection{Coefficients $\epsilon_{1}$ and $\epsilon_{2}$}

This subsection investigates the dependence of $\epsilon_{1}$ and $\epsilon_{2}$ on the adjustment-cost parameters $b_{k}$ and $b_{h}$ (reflected in $q_{k}^{*}$ and $q_{h}^{*}$ ). Let Specification 1 be defined by $\alpha=0.3, \eta=0.5, n=0.01 /$ year, $x=0.02 /$ year, $\delta=0.05 /$ year, $r=0.06 /$ year (Barro et al.'s [4] calibration), and $\omega=1$. One should keep in mind that not all combinations of $q_{k}^{*}$ and $q_{h}^{*}$ are economically relevant. First, we expect significantly larger adjustment costs for human capital than for physical capital, i.e., $q_{k}^{*}<q_{h}^{*} .{ }^{17}$ Second, the steady-state levels of adjustment costs should not be large for physical capital; empirical studies indicate that $q_{k}^{*}$ is likely to be well below $1.5{ }^{18}$ In this case, $\left|\epsilon_{1}\right|$ does not fall below 4 percent per year if $q_{h}<2.5$; it falls to 2.7 percent per year only if $q_{h}^{*} \rightarrow \infty ;\left|\epsilon_{2}\right|$ does not fall below 12 percent per year in this case. As discussed later, the rate of convergence is a weighted average of $\left|\epsilon_{1}\right|$ and $\left|\epsilon_{2}\right|$ (plausibly substantively closer to $\left|\epsilon_{1}\right|$ than to $\left.\left|\epsilon_{2}\right|\right)$ ). In order to make the model consistent with the low empirically observed convergence rate of about 2 percent per year, it is necessary to depart from Specification 1.

A simple numerical analysis of perturbations from Specification 1 shows that neither $\epsilon_{1}$ nor $\epsilon_{2}$ turns out to be very sensitive to $r$ : $\left|\epsilon_{1}\right|$ changes very slightly and ambiguously with $r ;\left|\epsilon_{2}\right|$ rises very slightly with $r$. Both $\left|\epsilon_{1}\right|$ and $\left|\epsilon_{2}\right|$ are positively related to $x, n$, and $\delta$, but they change less than proportionately with each of these parameters. ${ }^{19}$ Higher $\omega$ reduces both $\left|\epsilon_{1}\right|$ and $\left|\epsilon_{2}\right|$; this result is quite intuitive since $\omega$ indicates how sharply the adjustment costs change with the distance of the economy from its steady state. Higher capital shares, $\alpha$ and $\eta$, reduce $\left|\epsilon_{1}\right|$, but they practically do not affect $\left|\epsilon_{2}\right|$ - this coefficient reacts very slightly and ambiguously.

Let us consider two departures from Specification 1, namely Specification 2 with $\omega=3$ and the unchanged values of other parameters, and Specification 3 with $\eta=0.65$ and the unchanged values of other parameters (including $\omega=1$ ).

\footnotetext{
${ }^{17}$ This assumption is crucial. Unlike physical capital, which can be accumulated relatively quickly, human capital formation (learning) fundamentally takes time. See also Barro and Sala-i-Martin [3], pages 119 and 178.

${ }^{18}$ The $q$ values presented by Blanchard, Rhee, and Summers [6] and by Hayashi [10] never exceed 1.4 .

${ }^{19}$ Coefficients $\epsilon_{1}$ and $\epsilon_{2}$ are natural counterparts to the convergence coefficient in the basic neoclassical model. In a closed-economy neoclassical model with two types of capital and constant saving rates, the convergence coefficient is approximately $(1-\alpha-\eta)(x+n+\delta)$ (see Mankiw et al. [13]); this coefficient also changes less than proportionately with $x, n$, and $\delta$.
} 
In both these specifications, $\left|\epsilon_{1}\right|$ makes approximately 2 percent per year if $q_{h}^{*}$ is in the neighborhood of 2 . Generally it turns out that $\left|\epsilon_{1}\right|$ is not very sensitive to $q_{k}^{*}$ or $q_{h}^{*}$ if $q_{k}^{*}$ is low and $q_{h}^{*}$ high; on the other hand, $\left|\epsilon_{2}\right|$ is relatively sensitive to $q_{k}^{*}$ but insensitive to $q_{h}^{*}$ if $q_{k}^{*}$ is low and $q_{h}^{*}$ high.

\subsection{Growth and Convergence}

The time evolution of output per effective worker, $y$, is

$$
\ln \left(y / y^{*}\right)=\alpha \ln \left(k / k^{*}\right)+\eta \ln \left(h / h^{*}\right)=\Theta_{1} e^{\epsilon_{1} t}+\Theta_{2} e^{\epsilon_{2} t},
$$

where

$$
\begin{aligned}
& \Theta_{1}=\mu_{1}\left(\alpha+\eta \nu_{1,2}\right) \\
& \Theta_{2}=\mu_{2}\left(\alpha+\eta \nu_{2,2}\right)
\end{aligned}
$$

The growth rate of $y$ is

$$
\gamma=\frac{\dot{y}}{y}=\frac{d \ln \left(y / y^{*}\right)}{d t}=\Theta_{1} \epsilon_{1} e^{\epsilon_{1} t}+\Theta_{2} \epsilon_{2} e^{\epsilon_{2} t} .
$$

Recall that $\mu_{1}$ and $\mu_{2}$ (and, therefore, $\Theta_{1}$ and $\Theta_{2}$ ) are determined by the initial conditions $\left(k_{0}\right.$ and $\left.h_{0}\right)$, as reflected in equations (73) and (74). Without knowing these initial conditions, we cannot express $\gamma$ just in terms of $y / y^{*}$. This is what makes this model distinctive from the basic neoclassical model. Let

$$
m=\frac{h / h^{*}}{k / k^{*}}
$$

denote the ratio of human to physical capital with respect to its steady-state level. Equations (66) and (68) imply that

$$
\ln m=\left(\nu_{1,2}-1\right) \mu_{1} e^{\epsilon_{1} t}+\left(\nu_{2,2}-1\right) \mu_{2} e^{\epsilon_{2} t} .
$$

Equations (75)-(80) make it possible to express $\gamma$ in terms of $y / y^{*}$ and $m$ :

$$
\gamma=\frac{\epsilon_{1}-\epsilon_{2}}{\kappa_{1}-\kappa_{2}} \ln m+\frac{\kappa_{1} \epsilon_{2}-\kappa_{2} \epsilon_{1}}{\kappa_{1}-\kappa_{2}} \ln \left(y / y^{*}\right),
$$

where

$$
\begin{aligned}
& \kappa_{1}=\frac{\nu_{1,2}-1}{\alpha+\eta \nu_{1,2}}, \\
& \kappa_{2}=\frac{\nu_{2,2}-1}{\alpha+\eta \nu_{2,2}} .
\end{aligned}
$$


Equation (81) represents the major result of this paper. This equation identifies two economic forces of transitional dynamics. One force arises from the imbalances between human and physical capital [the term $\ln m$ ], whereas the other one corresponds to the ordinary neoclassical effect of diminishing returns to broad capital [conditional convergence reflected in the term $\ln \left(y / y^{*}\right)$ ].

Equations similar to (81) have been estimated in numerous empirical studies [the Barro regressions, where various explanatory variables (e.g., political stability, enforcement of property rights, market distortions, openness, population growth rate, terms of trade) typically account for the steady state, $\left.y^{*}\right] .{ }^{20}$ In these studies, measures of human capital are frequently added as important explanatory variables. The separable effect of the output level and the relative human-capital abundance on the growth rate predicted by the present model seems to provide a plausible rationale for these regressions. We expect that $m$ should contribute positively and $y / y^{*}$ should contribute negatively to $\gamma$. As shown later, this is really the case if $b_{h}>b_{k}$.

Let us introduce a concept of the convergence coefficient (rate of convergence). The convergence coefficient may be defined as a negative partial derivative of $\gamma$ with respect to $\ln y$. Holding $m$ fixed, this definition yields

$$
\beta \equiv-\left[\frac{\partial \gamma}{\partial(\ln y)}\right]_{m=\text { const. }}=\frac{\kappa_{1}\left|\epsilon_{2}\right|-\kappa_{2}\left|\epsilon_{1}\right|}{\kappa_{1}-\kappa_{2}}
$$

This $\beta$ shows how the growth rate changes with the output level once the humanphysical capital imbalances are accounted for. We can also introduce another concept of the convergence rate: the overall tendency of the economy to grow faster the further the economy is below its steady state can be indicated by ${ }^{21}$

$$
\tilde{\beta} \equiv-\frac{\gamma}{\ln \left(y / y^{*}\right)}
$$

Substituting (81) and (84) into this equation yields

$$
\tilde{\beta}=\beta-\frac{\left|\epsilon_{2}\right|-\left|\epsilon_{1}\right|}{\kappa_{1}-\kappa_{2}} M
$$

where

$$
M=\frac{\ln m}{\ln \left(y / y^{*}\right)} .
$$

\footnotetext{
${ }^{20}$ See, for example, Barro and Sala-i-Martin [3], Chapter 12.

${ }^{21}$ I have adopted this concept in Duczynski [8]. In this definition, the rate of convergence depends on the ratio of human to physical capital.
} 
We can also express $\tilde{\beta}$ as a function of time for given initial conditions:

$$
\tilde{\beta}=-\frac{\Theta_{1} \epsilon_{1} e^{\epsilon_{1} t}+\Theta_{2} \epsilon_{2} e^{\epsilon_{2} t}}{\Theta_{1} e^{\epsilon_{1} t}+\Theta_{2} e^{\epsilon_{2} t}}=\frac{\left|\epsilon_{1}\right|+\left|\epsilon_{2}\right| \frac{\Theta_{2}}{\Theta_{1}} e^{\left(\epsilon_{2}-\epsilon_{1}\right) t}}{1+\frac{\Theta_{2}}{\Theta_{1}} e^{\left(\epsilon_{2}-\epsilon_{1}\right) t}} .
$$

Note that $\tilde{\beta}$ is a time-dependent "weighted average" of $\left|\epsilon_{1}\right|$ and $\left|\epsilon_{2}\right|$. If $t \rightarrow \infty$, $\tilde{\beta} \rightarrow \min \left\{\left|\epsilon_{1}\right|,\left|\epsilon_{2}\right|\right\}=\left|\epsilon_{1}\right|$. Let $m_{0}$ denote the initial value of $m$ and, similarly, $M_{0}$ denote the initial value of $M$. Initial physical and human capital can be expressed in terms of initial output, $y_{0}$, and the imbalance coefficient, $m_{0}$ :

$$
\begin{aligned}
& \ln \left(k_{0} / k^{*}\right)=\frac{\ln \left(y_{0} / y^{*}\right)-\eta \ln m_{0}}{\alpha+\eta}, \\
& \ln \left(h_{0} / h^{*}\right)=\frac{\ln \left(y_{0} / y^{*}\right)+\alpha \ln m_{0}}{\alpha+\eta} .
\end{aligned}
$$

If this is substituted into (73), (74), (76), (77), and (88), $\tilde{\beta}$ can be expressed in terms of $M_{0}$ and time:

$$
\tilde{\beta}=\frac{\left|\epsilon_{1}\right|\left(-\kappa_{2}+M_{0}\right)+\left|\epsilon_{2}\right|\left(\kappa_{1}-M_{0}\right) e^{\left(\epsilon_{2}-\epsilon_{1}\right) t}}{-\kappa_{2}+M_{0}+\left(\kappa_{1}-M_{0}\right) e^{\left(\epsilon_{2}-\epsilon_{1}\right) t}} .
$$

The model's behavior critically depends on the ranges of parameters $\nu_{2,2}$ and $\nu_{1,2}$, which are determined in Lemma 1 and Lemma 2 (see the Appendix). The following propositions describe the dynamics of the model:

Proposition 1: Let $b_{k}<b_{h}$. The rate of growth of output per effective worker, $\gamma$, depends positively on $m$ and negatively on $y / y^{*}$.

Proof: Lemma 1 and Lemma 2 imply that $0<\kappa_{1}<(1-\alpha-\eta) / \eta$ and $-\infty<\kappa_{2}<-1 / \alpha$, i.e., $\kappa_{1}>0$ and $\kappa_{2}<0$. Because $\epsilon_{2}<\epsilon_{1}<0$, the proof follows directly from equation (81), Q.E.D.

Corollary: Let $b_{k}<b_{h}$. If $y<y^{*}\left(y>y^{*}\right), \tilde{\beta}$ is positively (negatively) related to $m$ for given $y / y^{*}$.

Proposition 2: If $b_{k}=b_{h}, \gamma$ is independent of $m$ and depends negatively on $y / y^{*}$; moreover, $\beta=\left|\epsilon_{1}\right|$ and $\tilde{\beta}=\left|\epsilon_{1}\right|$ for $y \neq y^{*}$.

Proof: Lemma 1 and Lemma 2 imply that $\kappa_{1} \rightarrow 0$ and $\kappa_{2} \rightarrow-\infty$ if $b_{k} \rightarrow b_{h}$. The proof follows from equations (81), (84), and (86), Q.E.D.

Proposition 3: Let $b_{k} \neq b_{h}$. There exists a critical level of $M_{0}$ for which $\tilde{\beta}$ equals $\left|\epsilon_{1}\right|$ and stays constant over time. This critical level of $M_{0}$ is equal to $\kappa_{1}$. 
Proof: It follows directly from (91).

Proposition 4: Let $b_{k} \neq b_{h}$. There exists a critical level of $M_{0}$ for which $\tilde{\beta}$ equals $\left|\epsilon_{2}\right|$ and stays constant over time. This critical level of $M_{0}$ is equal to $\kappa_{2}$.

Proof: It follows directly from (91).

Proposition 5: If $M_{0}>\kappa_{2}, \tilde{\beta}$ remains finite over time and converges monotonically towards $\left|\epsilon_{1}\right|$. If $M_{0}<\kappa_{2}, \tilde{\beta}$ reaches infinity in finite time, it turns to minus infinity, and only after that it converges monotonically from below towards $\left|\epsilon_{1}\right|$.

Proof: $\left(\kappa_{1}-M_{0}\right) /\left(M_{0}-\kappa_{2}\right)$ is greater (lower) than -1 if $M_{0}$ is greater (lower) than $\kappa_{2}$. Equation (91) then implies a smooth monotonic path for $\tilde{\beta}$ in the former case and a discontinuity of $\tilde{\beta}$ in the latter case, Q.E.D.

An important result of the present paper is that growth depends positively on the ratio of human to physical capital if the adjustment-cost parameter is higher for human than for physical capital (see Proposition 1). Conditional convergence is reflected in the negative relationship between $\gamma$ and $y / y^{*}$. Proposition 2 states that there are no imbalance effects if the adjustment-cost parameters are equal for both types of capital. Propositions 3 and 4 determine two critical initial conditions for which $\tilde{\beta}$ stays constant over time. Proposition 5 qualitatively describes the time evolution of $\tilde{\beta}$; note that the discontinuity of $\tilde{\beta}$ in the case of $M_{0}<\kappa_{2}$ occurs when $y$ crosses $y^{*}$ (the imbalance effect is strong enough to cause an overshooting of the steady state). ${ }^{22}$

Recall that Lemma 1 and Lemma 2 lead to $0<\kappa_{1}<(1-\alpha-\eta) / \eta$ and $-\infty<\kappa_{2}<-1 / \alpha$ for $b_{h}>b_{k}$, where $\kappa_{1} \rightarrow 0$ and $\kappa_{2} \rightarrow-\infty$ if $b_{k} \rightarrow b_{h}$. Therefore, $\left|\kappa_{1}\right|$ is likely to be significantly smaller than $\left|\kappa_{2}\right|$. Consequently, coefficient $\beta$ can be expected to be closer to $\left|\epsilon_{1}\right|$ than to $\left|\epsilon_{2}\right|$. Coefficient $\tilde{\beta}$ tends to be close to $\left|\epsilon_{1}\right|$ for economies which have $m$ close to 1 (i.e., which have $M$ close to 0 ).

\subsection{Illustrative Examples}

Let us illustrate the behavior of growth and convergence on Specifications 1, 2 , and 3. It remains to specify the adjustment-cost parameters, which should

\footnotetext{
${ }^{22}$ All propositions relate to the log-linearized model. This model does not differ much from the exact model if $y$ is close to $y^{*}$ and $m$ close to 1 .
} 
be chosen consistently with two empirical requirements. First, convergence is sufficiently slow (e.g., at the rate of about 2 percent per year) for Specifications 2 and 3 . Second, the steady-state value of Tobin's q for physical capital, $q_{k}^{*}$, is only slightly higher than $1 .^{23}$ These requirements are satisfied if, for example, $q_{k}^{*}=1.2$ and $q_{h}^{*}=2.0$. In this calibration, $\epsilon_{1} \doteq-0.048 /$ year and $\epsilon_{2} \doteq-0.181 /$ year in Specification $1, \epsilon_{1} \doteq-0.022 /$ year and $\epsilon_{2} \doteq-0.097 /$ year in Specification 2, and $\epsilon_{1} \doteq-0.019 /$ year and $\epsilon_{2} \doteq-0.183 /$ year in Specification 3 . The steady-state marginal products are $\left(\frac{\partial f}{\partial k}\right)^{*}=0.12 /$ year and $\left(\frac{\partial f}{\partial h}\right)^{*}=0.16 /$ year in Specification 2, and $\left(\frac{\partial f}{\partial k}\right)^{*}=0.124 /$ year and $\left(\frac{\partial f}{\partial h}\right)^{*}=0.18 /$ year in Specifications 1 and 3 . The critical levels of $M_{0}$ amount to $\kappa_{1} \doteq 0.27$ and $\kappa_{2} \doteq-4.95$ in Specification $1, \kappa_{1} \doteq 0.28$ and $\kappa_{2} \doteq-4.76$ in Specification 2 , and $\kappa_{1} \doteq 0.05$ and $\kappa_{2} \doteq-5.20$ in Specification 3. Convergence coefficients $\beta$ make approximately 0.055/year, 0.026/year, and 0.020/year in Specifications 1, 2 and 3, respectively.

Figures 1, 2, and 3 demonstrate the dependence of the per capita output growth rate, $\gamma+x$, on $m$ (ranging from 0.3 to 3.0) and $y / y^{*}$ (ranging from 0.5 to 2.0 ) in Specifications 1,2 , and 3 , respectively, if $q_{k}^{*}=1.2$ and $q_{h}^{*}=2.0$. As expected, growth depends positively on $m$ and negatively on $y / y^{*}$. Figures 4,5 , and 6 illustrate the time evolution of $y / y^{*}$ for the same specifications. Time is measured in years. The initial value of $y / y^{*}$ is assumed to be equal to 0.8. Each figure contains four graphs corresponding to $m_{0}$ equal to $0.5,1,2$, and 4 .

\section{Concluding Remarks}

The basic neoclassical growth model cannot properly describe the behavior of open economies with capital mobility. This paper demonstrates that the model becomes more realistic if a kind of capital (human capital) exists which is subject to large adjustment costs. If human capital cannot be changed rapidly, physical capital accumulation is discouraged due to the complementarity between human and physical capital. Conditional convergence is sufficiently slow for a certain range of parameter values.

A similar effect occurs in models with borrowing restrictions. Unlike these

\footnotetext{
${ }^{23}$ Of course, even if $q_{k}^{*}$ is sufficiently low, $q_{k}$ may be considerably larger initially. Because the empirical evidence suggesting low $q_{k}$ comes from developed economies which seem to be close to their steady states, we do not regard higher values of $q_{k}$ as necessarily counterfactual for highly-investing economies which are significantly below their steady states.
} 
models, the present analysis is not restricted to credit-constrained economies. For example, the empirically-observed slow convergence of the U.S. states (most of which are not likely to be credit constrained) can plausibly be explained in the present framework rather than in models with partial capital mobility.

It should be noted that sufficiently slow conditional convergence (e.g., at the rate of 2 percent per year) is not automatic in the present framework and requires specific parameter values. It should also be noted that adjustment costs alone cannot improve the well-known problematic asymptotic behavior of consumption and debt; nevertheless, introducing preference parameter variations or finite horizons, as described, for instance, in Chapter 3 of Barro and Sala-i-Martin's [3] book, would be a straightforward, relevant extension mitigating this problem.

The model allows for the analytical description of growth depending positively on the ratio of human to physical capital. The closed-form solution of the model, namely the separate effect of output and the human-physical ratio on the output growth rate, is consistent with the prominent branch of growth empirical literature. An interesting result of the present model is the possible overshooting of the steady state if the imbalance effect between human and physical capital is sufficiently strong.

The imbalance effects between human and physical capital have been discussed, for example, in the context of two-sector endogenous growth models. ${ }^{24}$ In these models, high ratios of human to physical capital typically have a positive effect on growth as a result of the relative human-capital intensity of the education sector. In comparison, the present paper illustrates how imbalance effects emerge if the costs of adjustment are larger for human than for physical capital accumulation. If these imbalance effects are combined with the neoclassical effects of diminishing returns, the growth dynamics turn out to be richer than the dynamics of the basic neoclassical model.

\footnotetext{
${ }^{24}$ See, for example, Mulligan and Sala-i-Martin [14].
} 


\section{Appendix}

Lemma 1: If $b_{k}<b_{h}$, then $-\alpha / \eta<\nu_{2,2}<0$. If $b_{k}=b_{h}$, then $\nu_{2,2}=-\alpha / \eta$.

Proof: Let $\Sigma_{k} \equiv \frac{1}{q_{k}^{*}}\left(\frac{\partial f}{\partial k}\right)^{*}$ and $\Sigma_{h} \equiv \frac{1}{q_{h}^{*}}\left(\frac{\partial f}{\partial h}\right)^{*}$. Because

$$
\begin{aligned}
& \Sigma_{k}=\frac{r+\delta+b_{k}(x+n+\delta)^{\omega}[r+\delta-(x+n+\delta) \omega /(1+\omega)]}{1+b_{k}(x+n+\delta)^{\omega}}, \\
& \Sigma_{h}=\frac{r+\delta+b_{h}(x+n+\delta)^{\omega}[r+\delta-(x+n+\delta) \omega /(1+\omega)]}{1+b_{h}(x+n+\delta)^{\omega}},
\end{aligned}
$$

we have $\Sigma_{k}>\Sigma_{h}$ if $b_{k}<b_{h}$, and $\Sigma_{k}=\Sigma_{h}$ if $b_{k}=b_{h}$. A similar comparison can be made between $\mathcal{A}$ and $\mathcal{E}$ :

$$
\begin{aligned}
& \mathcal{A}=\frac{\left[1+b_{k}(x+n+\delta)^{\omega}\right](x+n+\delta)^{1-\omega}}{b_{k} \omega}, \\
& \mathcal{E}=\frac{\left[1+b_{h}(x+n+\delta)^{\omega}\right](x+n+\delta)^{1-\omega}}{b_{h} \omega},
\end{aligned}
$$

and, therefore, $\mathcal{A}>\mathcal{E}$ for $b_{k}<b_{h}$, and $\mathcal{A}=\mathcal{E}$ for $b_{k}=b_{h}$. Let us introduce two parameters, $\rho_{1}$ and $\rho_{2}$ :

$$
\begin{gathered}
1+\rho_{1} \equiv \mathcal{A} / \mathcal{E}, \\
1+\rho_{2} \equiv \Sigma_{k} / \Sigma_{h} .
\end{gathered}
$$

From (71) and (64), $\nu_{2,2}$ is given by

$$
\nu_{2,2}=\frac{1-\alpha}{2 \eta}+\frac{1-\eta+\sqrt{[(1-\alpha) / \tau+1-\eta]^{2}-4(1-\alpha-\eta) / \tau}}{-2 \eta / \tau},
$$

where $1 / \tau=\left(1+\rho_{1}\right)\left(1+\rho_{2}\right)$. Simple algebra can show that the argument of the square root is positive for $0<\tau \leq 1$, i.e., $\nu_{2,2}$ is well defined on this interval. The second part of Lemma 1 follows directly if we substitute $\tau=1$. The inequality $-\alpha / \eta<\nu_{2,2}$ from the first part of Lemma 1 will be proven if we show that $\nu_{2,2}$ is decreasing in $\tau$ for $0<\tau \leq 1$. This is satisfied if the function

$$
g(\tau)=(1-\eta) \tau+\sqrt{[(1-\alpha)+(1-\eta) \tau]^{2}-4(1-\alpha-\eta) \tau}
$$

is increasing in $\tau$ for $0<\tau \leq 1$. The first derivative of $g(\tau)$ is greater than 0 if and only if

$(1-\eta) \sqrt{[(1-\alpha)+(1-\eta) \tau]^{2}-4(1-\alpha-\eta) \tau}>2(1-\alpha-\eta)-(1-\eta)[(1-\alpha)+(1-\eta) \tau]$. 
If the right-hand side is negative, the inequality is trivially satisfied. If the righthand side is nonnegative, the inequality turns out to be equivalent to $\alpha \eta>0$, which is again trivially satisfied. Therefore, $g(\tau)$ is increasing, and $\nu_{2,2}>-\alpha / \eta$ for $b_{k}<b_{h}$. The inequality $\nu_{2,2}<0$ then follows from the monotonicity of $\nu_{2,2}$ in $\tau$ and the limit $\nu_{2,2} \rightarrow 0$ for $\tau \rightarrow 0$, Q.E.D.

Lemma 2: If $b_{k}<b_{h}$, then $1<\nu_{1,2}<(1-\alpha) / \eta$. If $b_{k}=b_{h}$, then $\nu_{1,2}=1$.

Proof: Following the proof of Lemma 1, $\nu_{1,2}$ is given by

$$
\nu_{1,2}=\frac{1-\alpha}{2 \eta}+\frac{1-\eta-\sqrt{[(1-\alpha) / \tau+1-\eta]^{2}-4(1-\alpha-\eta) / \tau}}{-2 \eta / \tau} .
$$

The second part of Lemma 2 is obtained directly if we substitute $\tau=1$. A procedure similar to that in the proof of Lemma 1 can show that $\nu_{1,2}$ is decreasing in $\tau$, from which it follows that $1<\nu_{1,2}$ for $0<\tau<1$. Finally, the limit $\nu_{1,2} \rightarrow(1-\alpha) / \eta$ for $\tau \rightarrow 0$ implies the inequality $\nu_{1,2}<(1-\alpha) / \eta$, Q.E.D. 


\section{References}

[1] Abel, Andrew and Olivier Blanchard (1983). "An Intertemporal Equilibrium Model of Saving and Investment," Econometrica, 51, 3, 675-692.

[2] Barro, Robert J. (1991). "Economic Growth in a Cross Section of Countries," Quarterly Journal of Economics, 106, 2, 407-443.

[3] Barro, Robert J. and Xavier Sala-i-Martin (1995). Economic Growth, Boston, MA, McGraw-Hill.

[4] Barro, Robert J., N. Gregory Mankiw, and Xavier Sala-i-Martin (1995). "Capital Mobility in Neoclassical Models of Growth," American Economic Review, 85, 1, 103-115.

[5] Blanchard, Olivier and Stanley Fischer (1993). Lectures on Macroeconomics, Cambridge, MA, MIT Press.

[6] Blanchard, Olivier, Changyong Rhee, and Lawrence H. Summers (1993). "The Stock Market, Profit, and Investment," Quarterly Journal of Economics, 108, 1, 115-136.

[7] Caballe, Jordi and Manuel S. Santos (1993). "On Endogenous Growth with Physical and Human Capital," Journal of Political Economy, 101, 6, 10421067.

[8] Duczynski, Petr (1997). "Convergence in Neoclassical Models with Capital Mobility and Two Kinds of Capital," Bulletin of the Czech Econometric Society, 6, 47-68.

[9] Duczynski, Petr (1998). "Capital Mobility in Neoclassical Models of Growth: Comment," mimeo, Charles University, Czech Republic.

[10] Hayashi, Fumio (1982). "Tobin's Marginal q and Average q: A Neoclassical Interpretation," Econometrica, 50, 1, 213-224.

[11] Kremer, Michael and James Thomson (1998). "Why Isn't Convergence Instantaneous? Young Workers, Old Workers, and Gradual Adjustment," Journal of Economic Growth, 3, 1, 5-28. 
[12] Lucas, Robert E., Jr. (1990). "Why Doesn't Capital Flow from Rich to Poor Countries?" American Economic Review: Papers and Proceedings, 80, 92-96.

[13] Mankiw, N. Gregory, David Romer, and David N. Weil (1992). "A Contribution to the Empirics of Economic Growth," Quarterly Journal of Economics, 107, 2, 407-437.

[14] Mulligan, Casey B. and Xavier Sala-i-Martin (1993). "Transitional Dynamics in Two-Sector Models of Endogenous Growth," Quarterly Journal of Economics, 108, 3, 737-773.

[15] Solow, Robert M. (1956). "A Contribution to the Theory of Economic Growth," Quarterly Journal of Economics, 70, 1, 65-94. 
Figures 1,2, and 3: Per capita output growth as a function of $\mathrm{m}$ and $\mathrm{y} / \mathrm{y}^{*}$ for Specifications 1,2 , and 3 , respectively

Figure 1

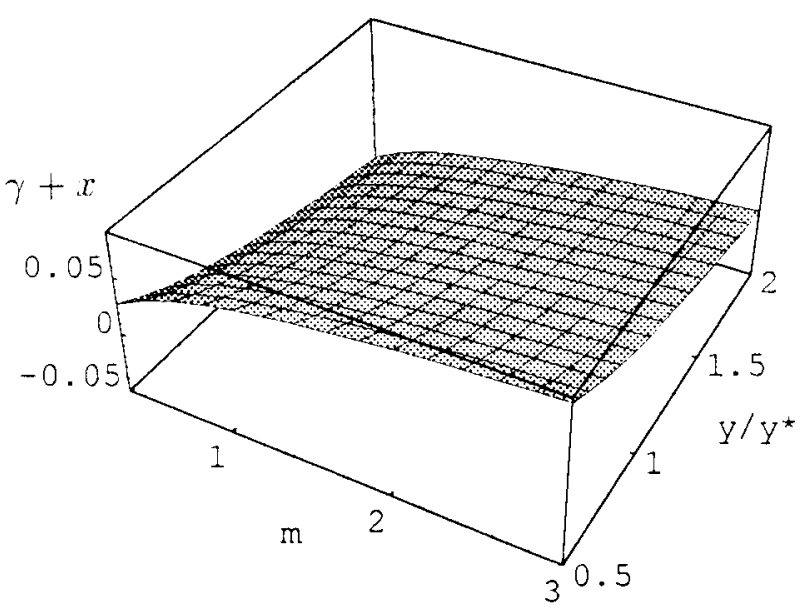

Figure 2

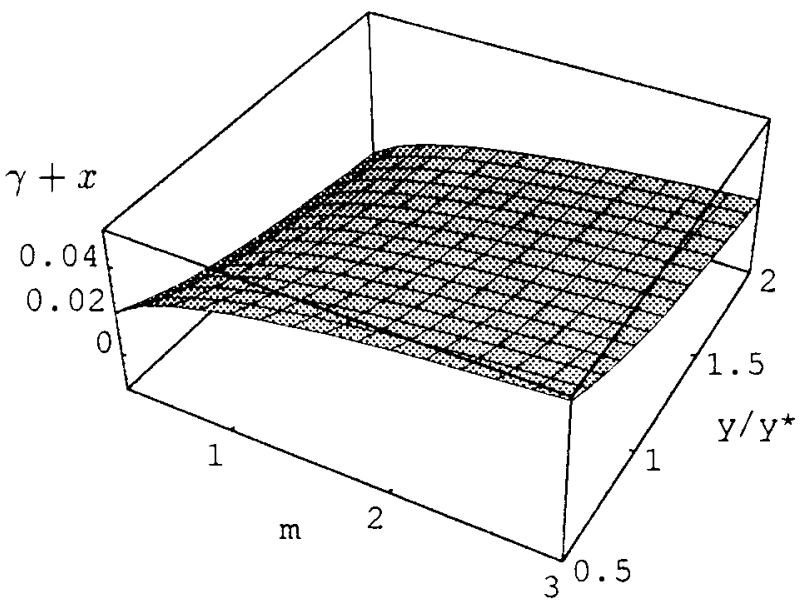

Eigure 3

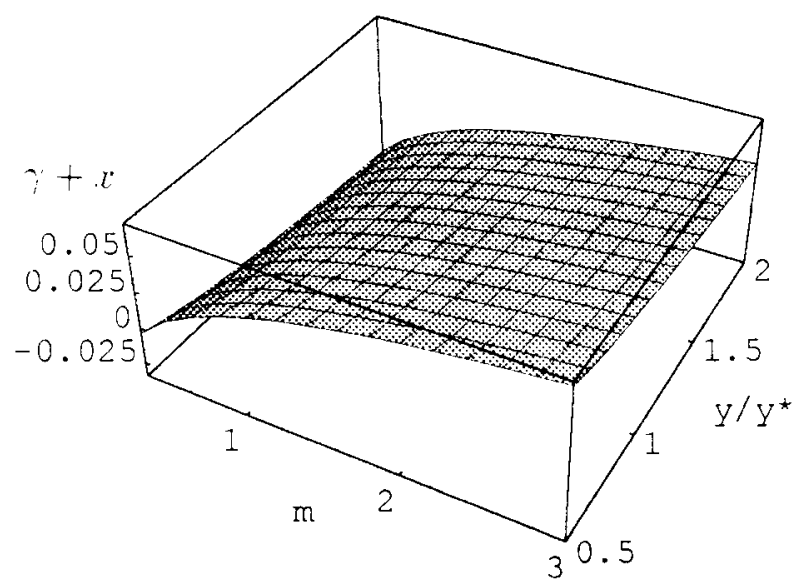


Figures 4,5, and 6: The evolution of output per effective capita for Specifications 1,2, and 3, respectively, for given adjustment-cost parameters and various human-physical ratios, given by $\mathrm{m}=0.5$ (dot-dashed), $m=1$ (full), $m=2$ (dashed), and $m=4$ (dotted).

\section{Figure 4}

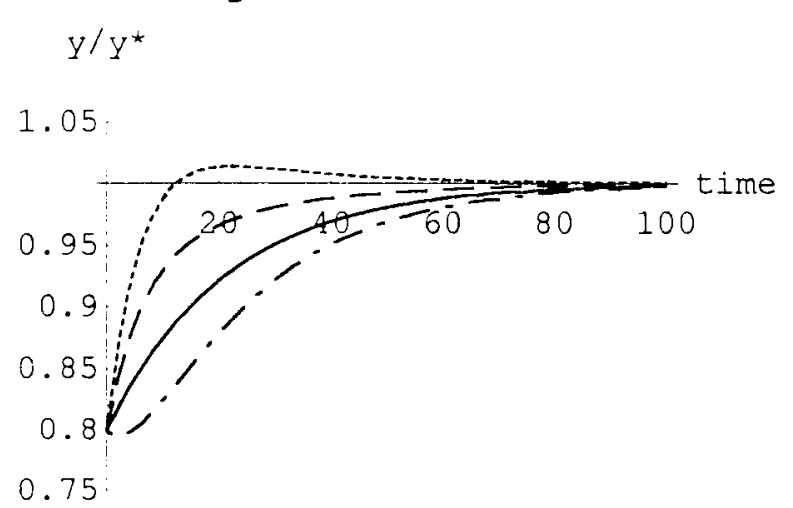

Eigure 5

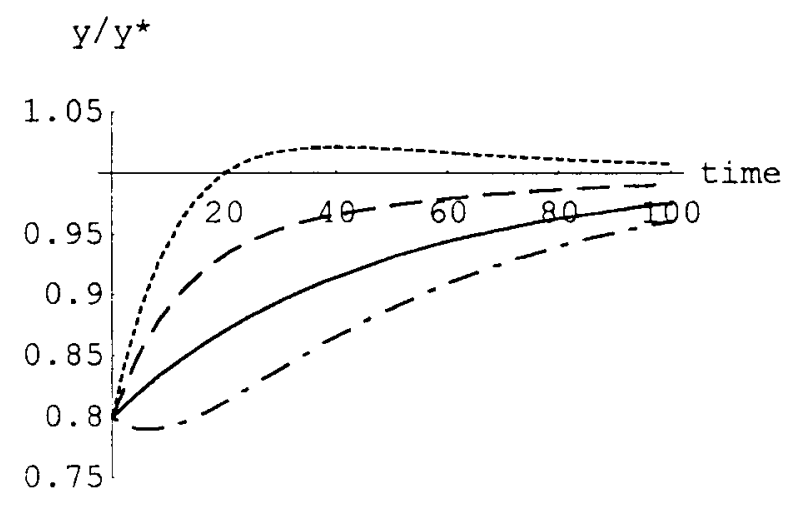

Figure 6

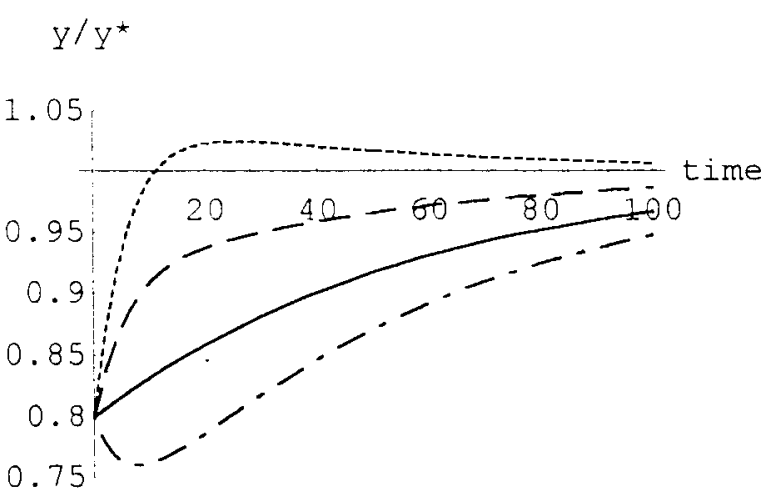

